[F. Lafarga, L. Pegenaute\&E. Gallén, ed. Interacciones entre las literaturas ibéricas

Vol. 3. Peter Lang, 2010. 493-510]

\title{
La fortuna de Ramón de la Cruz en el teatre català vuitcentista: els inicis de Josep Robrenyo*
}

\author{
Gabriel Sansano \\ Universitat d'Alacant/IIFV
}

Fa un parell d'anys aproximadament que vam començar a interrogar-nos sobre la recepció de l'obra dels dramaturgs populars espanyols de la segona meitat del segle XVIII (Ramón de la Cruz, Juan Ignacio González del Castillo, Luis Moncín, Vicente Rodríguez de Arellano, Sebastián Vázquez, Llucià F. Comella, José Concha, etc), en l'escena catalana del segle XIX. Així vaig començar a estudiar el tema seguint tres línies de treball: a) la posada en escena de les obres d'aquests autors a través de les cartelleres conegudes; b) la difusió d'aquelles obres a través de l'edició en plecs de comèdies; i c) les traduccions i reescriptures concretes que en feren els poetes dramàtics catalans.

En un altre lloc ja hem exposat com enfront d'alguns dramaturgs catalans populars del pas del segle XVIII al XIX, del tipus Roca i Seguí, Joan Baptista Escorihuela, Vicent Branchart, Carles Leon, Manuel Andreu o Ignasi Plana, sembla sorgir un grup de dramaturgs relativament distanciats dels anteriors, format per Josep Robrenyo, Vicent Albertí, Francesc Renart i Arús, Bernat i Baldoví, Antoni Bisañes (i continuada per Ramon Lladró, Eduard Escalante, Pere d'A. Penya o Bartomeu Ferrà, etc.), que suposa una dramàtica força coherent i coetània arreu dels Països Catalans, a pesar del desconeixement mutu (vegeu Sansano: en premsa).

Es tracta d'un corrent de revitalització de l'escena autòctona, un "teatre" fins a cert punt diferent als dels primers (malgrat els deutes evidents amb el teatre antic que puguem observar en alguns casos), però que seguia de prop determinats models del

\footnotetext{
* Aquesta comunicació s'emmarca en la realització del projecte "La literatura catalana en el Ochocientos: liberalismo, renaixença(ces), modernidad" (Ministerio de Ciencia e Innovación, FFI2008-01548/FILO). Vull agrair a Anna Vázquez i a Manuel Llanas la seua amabilitat i ajut quant a la localització d'alguns títols i pels aclariments quant als impressors del segle XVIII.
} 
sainete castellà. Aquests acabaran desplaçant als primers i crearan un públic per a la generació o nòmina de dramaturgs que començaran a ser el referent de l'escena catalana a partir de la dècada dels 50-60, encapçalats per Frederic Soler i els seus amics, associats i detractors, els quals apostaran ja per una obra més ambiciosa, diferenciada dels precedents esmentats més amunt i que, gradualment, començarà a ser plenament conscient de la seua escriptura teatral.

En aquesta comunicació vull exposar el resultat concret d'acarar la difusió de l'obra de Ramón de la Cruz a Catalunya, relacionant-la amb els inicis de Josep Robrenyo com a autor teatral i, més concretament, amb la seua obra bilingüe Juan y Eulalia, o El sarau de la Patacada. El resultat és el de constatar la línia que separa els dramaturgs "hereus o continuadors" del vell entremés, d'aquells altres que adopten els models provinents del sainete espanyol, ja d'ambients realistes o costumistes. No obstant això, també volem afegir que aquesta recerca no ha fet més que començar, i que per això mateix són hipòtesis que posem damunt de la taula de debat.

\section{Un punt de partida}

Si acarem les diverses cartelleres que en els darrers anys s'han pogut reconstruir, ens trobarem amb un panorama que, si fa no fa, a la fi del segle XVIII, segons Josep Maria Sala -que ha estudiat la cartellera de Barcelona de la darrera dècada del XVIII i primeres del XIX-, es pot resumir de la manera següent:

Así, entre 1790 y 1799, el peso del teatro barroco -160 obras de las 387- es enorme, y muchas comedias del XVII y primer tercio del XVIII forman parte del repertorio más socorrido, y todavía falta la eclosión de la comedia sentimental, que llenará de traducciones los tablados españoles y decantará a partir de 1800 la balanza a favor del teatro francés sobre el italiano. [...] En las postrimerías del Setecientos, se aplaude el espectáculo de magia o los efectos y desfiles "históricos" de las acciones historicomilitares. [...] Veintinueve autores más o menos coetáneos suministran las necesidades de un público. (2000: 62)

Això al marge, els models de teatre breu heretats del segle anterior essencialment eren dos: l'entremés i el sainet. El primer havia caigut en desús i ja es considerava antic i de mal gust, fins al punt que va ser retirat dels escenaris comercials cap al 1780. El sainet, 
sense tenir massa diferències amb aquell, apareixia com una peça nova o renovada després d'haver passat per les mans de Ramón de la Cruz i companyia. No obstant això, fins al primer terç del segle XIX ens trobem que els mateixos títols -sobretot si eixien de la impremta- unes vegades eren designats com a entremesos $i$ altres com a sainets $i$, de fet, se'n conserven molts testimonis, tant manuscrits com, sobretot, impresos. Finalment s'acabarà imposant el terme sainet, que no és altra cosa que un quadre de costums amb uns plantejaments molt esquemàtics i de caràcter jocós.

Com és sabut, Josep Robrenyo (Barcelona, 1783-1838) fou un dels primers a escriure i representar amb èxit una peça que ja no seguia el vell esquema de l'entremés, sinó que plantejava situacions noves i apuntava tipus dramàtics nous, amb l'obra Juan y Eulalia o La Laieta de Sant Just. De més a més, s'hi ha posat en relleu el seu teatre polític o revolucionari, escrit i representat en el context del Trienni Liberal o de la primera Guerra Carlina, i s'hi ha remarcat l'interés del seu teatre costumista. Potser, el que no s'han aclarit suficientment són els models dramàtics que fa servir en les seues peces costumistes, sobretot en la primera.

Si no s'hi ha investigat, no serà perquè l'erudit teatral Francesc Curet no remarcara fa gairebé cent anys (1917: 84) d'on havia eixit l'obra de Robenyo. Segons aquell, en escriure El sarau de la Patacada, Robrenyo

se había penetrado mucho de las producciones de Ramón de la Cruz, especialmente de El café de máscaras. Los personajes catalanes que intervienen en el Sarau de la Patacada, conservan la peculiar fisonomía de los ciudadanos barceloneses y los forasteros no se presentan como altaneros y despreciativos para con las costumbres de la ciudad, sino casi identificados con ellas, siguiendo la ley constante de que todas las corrientes emigratorias que vienen a parar a Barcelona, asimílanse en definitiva a la naturaleza catalana. Aparece en el Sarau el "lechuguino", variedad barcelonesa del "sietemesino", y muchas de las frases y donaires que figuran en la obra, son de repertorio todavía en el vocabulario de nuestras clases populares.

La font, el model dramàtic, semblava assenyalada clarament. Si de cas, faltava per determinar o delimitar el com i fins a quin punt s'hi seguia el model. No obstant això, la crítica posterior que es va interessar per l'obra va diluir aquesta línia interpretativa a la 
recerca de testimonis sobre els diversos saraos o balls de màscares que existien en l'època, per tal de ratificar el que l'obra tenia de realista o de retrat costumista del moment, prescindint-hi de si el model era original o manllevat. I de fet, de resultes de l'èxit d'El sarao de la Patacada, aquestes expansions ciutadanes ludicofestives ens han arribat relativament ben documentades a través dels escriptors costumistes com Robert Robert (1935) o folkloristes com Joan Amades (1937) i Rossend Llates (1944), entre altres.

\section{Ramón de la Cruz i el teatre català}

El poeta dramàtic Ramón de la Cruz (Madrid, 1731-1794) és un autor popular ben conegut al llarg de la segona meitat del segle XVIII i pràcticament tot el segle XIX per l'empremta que va deixar en el teatre costumista i de caràcter populista. Tan sols cal recordar que, entre obres originals i adaptacions de peces estrangeres, entre sainets, lloes, entremesos, tragèdies burlesques, etc., passen de 450 els títols que li són atribuïts. Obres representades assíduament en el període indicat i de les quals com a mínim dues dotzenes foren impreses reiteradament, bé amb el nom de l'autor, bé com a anònimes, i moltes altres estrafetes o apedaçades. ${ }^{1}$

Malgrat que Sala Valldaura (2007: 32) ens ha advertit que "Ramón de la Cruz fou el sainetista més representat $\mathrm{i}$ aplaudit a Barcelona durant diverses dècades, sens dubte durant l'última del Set-cents i les tres primeres del Vuit-cents", en el teatre català el nom d'aquest dramaturg madrileny sempre va lligat a la peça El café de Barcelona, obra d'encàrrec per celebrar l'onomàstica del rei Carles III i la reconstrucció del Teatre de Barcelona, l'any $1788 .^{2}$ Es tracta d'un títol que els historiadors del teatre català no han deixat mai de ressenyar. Així, per a Xavier Fàbregas (1975: 93),

El més simptomàtic és que un saineter madrileny com Ramón de la Cruz, quan ha d'estrenar al Teatre de la Santa Creu escriu obres bilingües car fer parlar en

\footnotetext{
${ }^{1}$ La bibliografia sobre Ramón de la Cruz s'ha vist incrementada en els darrers vint anys de forma notable. El lector interessat pot trobar anàlisi crítica i bibliografia complementària en Ramón de la Cruz, Sainetes, edició a cura de F. Lafarga (Madrid, Cátedra, 1990), o Sainetes, edició a cura de J. M. Sala Valldaura i estudi de M. Coulon (Barcelona, Crítica, 1996).

${ }^{2}$ Ramón de la Cruz y Cano, El café de Barcelona. Comedia en un acto, para representarse en el Teatro Nuevo de dicha ciudad el dia que se estrena, 4 de Noviembre de 1788, en celebridad de Nuestro Cathólico Monarca, Carlos Tercero. Escrita de orden del Excelentísimo Conde del Asalto, Capitán General de Cataluña, Barcelona, por Francisco Generas. La música era de Blas de la Serna, "compositor de los teatros de la Villa de Madrid".
} 
castellà els personatges catalans contravenia els més elementals principis de la versemblança. Així, escriu El café de Barcelona (1788), peça que té l'honor d'inaugurar el nou teatre acabat de construir, i La Maonesa (1783), que celebra la conquesta de Menorca pels espanyols, i a les dues peces el català hi està present. La intervenció de Ramón de la Cruz al nostre teatre és sens dubte anecdòtica. Però resulta molt simptomàtica. I ens ajuda a comprendre l'ascendent dels saineters catalans de finals del XVIII i començament del XIX.

Més recentment, Francesc Massip (2007: 318-321) ha tornat a insistir en l'interés que suposa la incorporació del català en aquesta obra:

Per això també, quan per reinaugurar el Teatre de la Santa Creu s'encarrega una peça al saineter madrileny Ramón de la Cruz (1731-94), ha d'escriure un sainet bilingüe perquè fer parlar en castellà els personatges catalans contravenia els més elementals principis de la versemblança, cosa que ja havia fet el mateix autor a Las Mahonesas (1783) que celebrava el retorn de Menorca a la corona hispànica.

Massip, que reprodueix l'inici de l'escena I i un fragment de la III d'El café de Barcelona, conclou amb la següent afirmació:

Intervencions en català les de Ramón de la Cruz sens dubte anecdòtiques, però que es feien eco de la vitalitat que començaven a cobrar a la capital els sainets en la llengua autòctona que en l'últim quart del segle solen donar-se en representacions privades, almenys de tres tipus... (321)

Des del nostre punt de vista, la utilització del català per part del saineter madrileny ha estat sobrevalorada tradicionalment. Només cal llegir la primera de les dues obres, Las mahonesas (1782), ${ }^{3}$ també d'encàrrec, en un acte i clarament propagandista de les glòries de la Corona per la recuperació de Menorca, per comprovar que la presència del

\footnotetext{
${ }^{3}$ L'única edició de l'obra és la de Palma, Josep Tous, 1900, reproduïda a Ciutadella, per Edicions Nura, 1988. També es pot consultar a $<$ books.google.com $>$.
} 
català es limita a cinc mots. La jove protagonista, interpretada per l'actriu Polonia, ${ }^{4}$ ix de la casa i s'adreça al seu pare que és 1'actor Espejo, en el breu diàleg següent: ${ }^{5}$

Polonia: Pare, tinga molt bon hora.

Espejo: Como me hables otra letra

que no sea castellano,

te he de romper la cabeza; (p. 14)

Aquest és tot el català de l'obra i, a més, l'autor, endut per l'exaltació patriòtica i heroica del moment (o no), no sembla deixar massa dubtes sobre l'opinió que li mereix la llengua maonesa. És clar que l'obra, a diferència d'El café s'havia de representar a Madrid, i no a la ciutat on està ambientada l'acció.

Pel que fa al segon cas -que cal recordar que ja fou objecte d'una breu reflexió per part de Joan Castells i Altirriba (1975)-, ${ }^{6}$ és cert que l'ús del català és més generós, tot i que només són dos els personatges que el parlen d'una forma significativa: la mestressa del café i el batlle. La intervenció catalana de la primera, pràcticament es limita al fragment reproduït per Castells (22) i per Massip (320) -i a alguna altra quarteta o resposta esparsa, gairebé sempre cantada, en total uns 30 versos mal comptats- en el qual s'exalten les figures de Carles III i del comte de l'Asalt, que és qui paga la festa, com es pot veure en el peu d'impremta. Per ser ja coneguts aquests versos, no els repetirem.

L'altre personatge significatiu, el Batlle, és definit pel mateix dramaturg en boca d'un altre personatge, el Médico: "Según de refranes echa / parece usté el Sancho Panza / catalán". I és això l'única cosa que fa aquest personatge que és al café i que parla, gairebé sempre, amb el metge: respondre amb una sentència, una parèmia, un adagi, etc. Realment no conversa, simplement introdueix l'element local. El metge pregunta i el batlle respon sentenciosament. Vegem-ne alguns exemples trets de l'escena tercera:

\footnotetext{
${ }^{4}$ En les obres de Ramón de la Cruz és habitual que els personatges prenguen el nom de l'actor i de l'actriu de la companyia per a la qual escrivia, i segons els tipus que aquests hi representaven, determinaven el caràcter del personatge: jove, vell, graciós, etc.

${ }^{5}$ Pose en lletra cursiva les intervencions catalanes per contrastar-les més nítidament.

${ }^{6}$ Cal fer notar però, que l'estudi de Castells i Altirriba no es fa a partir de l'edició original, sinó d'una còpia de l'obra impresa, com es desprén de la n. 7 del seu estudi.
} 
Médico: Y Usted tampoco ha venido aquí desde la Primavera?

Bayle: Lo pagés sempre ha de estar prop dels que fa treballar. Médico: Y por qué no se presenta oy en la ciudad más guapo, un Bayle, que es la primera persona de su lugar.

Bayle: Per rahons molt discretas que va sentir als meus pares y encara me recordo bé d'ellas. "Segons tindràs lo estament vestiràs honestament.

Qui ab vestits se gasta massa, té lo cap de carabaza.

Qui compra més del que pot aprés se ha de vendre tot. Procura tenir cabal per no anar al Hospital." Vol més?

Médico: No. Basta.

Bayle: Echeterà.

Médico: Mientras me tomo el café,

dígame si será cierta

la noticia que ha corrido contra una vecina vuestra.

Bayle: La primera informació no la creu el bon baró.

Médico: Con todo, aquí no lo oye, podemos murmurar de ella.

Bayle: Bellaco entreteniment és dir mal del qu·és ausent. (esc. III, pp. 10-11) 
De fet, Castells (1975: 23-24) enumera els 39 versos que, normalment, es resolen en un rodolí i que gairebé són tots els parlaments del batlle. No obstant això, la consideració de Ramón de la Cruz sobre el català, que podem relacionar amb la cita de l'obra de l'any 1783 que hem reproduït, queda ben palesa en els versos següents. Parlen la Maja i la Cafetera (que, de vegades, és designada també com a Patrona), i aquesta respon:

\author{
Cafetera: Mare de Déu! \\ Maja: No hablemos en la monserga \\ catalana; pues la sabe, \\ hábleme siempre en la lengua \\ castellana. (esc. IV, p. 17)
}

Vist amb un cert detall la presència del català en les dues obres esmentades, sembla evident que tradicionalment s'hi ha produït una sobrevaloració o que, simplement, les obres no han estat llegides en el seu context concret. És més, creiem que podem concloure que aquests dos episodis aïllats del saineter castellà tenen molt poc a veure amb la introducció gradual del català a l'escena oficial catalana de l'últim terç del segle XVIII. No creiem que siguen ni un esperó, ni un exemple per a l'escena autòctona.

Però, no obstant això, sí que ens permeten de recuperar els mots de Fàbregas segons els quals la intervenció de Ramón de la Cruz en el nostre teatre ens ajuda a comprendre l'ascendent dels saineters catalans de finals del XVIII i començament del XIX. Tot i que d'una manera intuïtiva, Fàbregas venia a incidir en les paraules citades de Francesc Curet, les quals relacionaven Ramón de la Cruz i Josep Robrenyo, a través d'El sarao de la Patacada. Però abans d'acarar aquest dos autors, ens agradaria parlar una mica més de la presència del català en l'escena comercial.

3. De l'escena espanyola a l'escena catalana

El mateix any en què es va representar El café de Barcelona, es va posar en escena un altre sainet que ens ha cridat l'atenció per diverses raons. La primera, pel títol, Saynete nuevo intitulado Los saraos de compañeros que se hacen en Barcelona, de Juan Manuel 
Martínez. ${ }^{7}$ La segona, perquè és un sainet bilingüe, una mica diferent de l'anterior i, la tercera, perquè quan acarem els actors que van representar el primer en el Teatre de Barcelona i el segon no sabem on, resulta que fins a cinc membres de la companyia són els mateixos que van estrenar l'obra feta en l'onomàstica de Carles III, i 10, pel cap baix, són habituals de les companyies que ocupen el teatre entre 1785 i 1788 (Par 1929: 502-512), amb la qual cosa cal concloure que aquest segon també es va representar en el teatre de Barcelona, el mateix any que es va estampar. Finalment, també ens ha interessat perquè fins ara ningú no ha fet esment d'aquesta obra en relació al teatre català.

Pel que fa a l'autor, segons Fernández Gómez (1993), Juan Manuel Martínez fou apuntador (si més no entre 1788-1792) i autor de comèdies, així com de dos sainets, el que acabe de comentar i La función del lugar, tot i que se li n'han atribuït alguns altres que no són seus. Cal dir que en la companyia espanyola formada en el teatre de Barcelona per a l'any 1788, figura un tal Juan Martínez, en qualitat de segon apuntador, que bé podria ser aquest autor (Par 1929: 512).

L'obra planteja un argument mínim al voltant de l'assistència a un sarau domèstic que hi ha organitzat, la ronda dels joves a les possibles candidates, incloent-hi la filla de qui organitza la festa, i conclou amb una censura dels excessos que habitualment es produeixen en aquesta mena de funcions casolanes. El que té de singular, des del punt de vista idiomàtic, i en contraposició a l'obra de Ramón de la Cruz, és que en aquest sainet, d'una banda, l'ús del català és més genuí i fluït (la referència a alguns personatges pels seus noms catalans: Tonet, Pauet, Puneta; les referències urbanes: carrer d'en Robador, carrer de Montcada, carrer del Regumí; als oficis: sastresa, cutaire, passamanera, masovera, així ho demostren); de l'altra, perquè les intervencions catalanes són més flexibles i naturals que les que havíem vist en l'obra del madrileny, fins al punt que dos personatges dialoguen entre ells en català, cosa que en aquella no s'esdevenia. Vegem-ne un exemple:

Pau. Senyora, què té que fa

\footnotetext{
7 Estampat a Barcelona per la Viuda Piferrer, “impresora del Rey". Per a tot el tema d'impremta, i específicament sobre aquest cas, vegeu Manuel Llanas, L'edició a Catalunya: el segle XVIII, amb la col·laboració de M. Ayats, Barcelona, Gremi d'Editors de Catalunya, 2003, pp. 127 i següents. Es tracta d'un títol que ja havia estat advertit per Villalonga (2008: 63).
} 
aqueixa cara tan sèria?

Pona. Ay!, yo, no senyor, se enganya.

Estic mirant la mestresa

de así com balla.

Pau. Y que tu

no saps?

Pona. $\quad$ En la meva terra

currandas, vall pla, rullet

y un vall d'a quatre en las festas

majors és lo que usem.

Pau. Eres casada u promesa?

Pona. Mire, els homes, de una pobre, fugen, ara cel y terra.

Pau. Pues yo sé un que te estima ab tot lo seu cor, pagesa.

Pona. Baya, no em diga exas cosa que em fa turnar roxa. (pp. 15-16)

Finalment (i com veurem després amb detall), ací s'incrementa l'entorn autòcton i els versos catalans superen en poc la part catalana d'El café de Barcelona. Fins i tot Martínez, a diferència de Cruz, es permet un elogi xicotet de la llengua catalana:

Pau. Calla tonto y oye una copla muy vieja en nuestro buen catalán.

Los 2. Dínosla, a qué esperas.

Pau. El que diu mal de les dones És cert que no té raó, Per a mi totes són bones, Mal viatxe la millor. (p. 7)

En relació a les peces breus a través de les quals el català va pujant als escenaris formals, cal recordar que la musicòloga Aurèlia Pessarrodona (2008) ha localitzat i 
estudiat quatre tonadilles (peces breus de teatre musical, una mena d'intermedi de caràcter jocós, cantat a una o diverses veus, molt de moda en el darrer terç del segle XVIII i el primer del XIX), de caràcter bilingüe, un fet que fins aquest moment no ha estat remarcat. Es tracta de La ramilletera (ca. 1773-1775); Las voluntarias de Barcelona (1774); Las vivanderas celosas (1778), i La italiana y el español (1778).

Una obra com aquesta de l'apuntador Juan Manuel Martínez, així com els altres casos ressenyats per Pessarrodona, palesen fins a quin punt, a partir d'un moment concret de la segona meitat del segle XVIII, era habitual que les companyies del Teatre de Barcelona feren concessions al públic i a l'idioma de la ciutat, en les peces breus que acompanyaven la comèdia, la tragèdia, etc. Ens sembla clar que si les peces no són excepcions sinó que apunten una continuïtat, és perquè eren molt del gust del públic i la companyia, predominantment castellana, s'hi esforçava per complaure'l (i per atraure'l). Tampoc no fóra estrany que entre els noms del repartiment de l'obra que no hem pogut identificar n'hi haguera cap d'aficionats locals que hi mataven el cuquet del teatre, alhora que eren utilitzats per la companyia per atraure més públic entre els familiars, els coneguts i el veïnat d'aquests. Si més no, això era una pràctica habitual al teatre de la Botiga de la Balda de València en l'últim terç del segle XVIII.

Vist tot això (no disposem d'espai per a explicar-ho amb més detall) se'ns planteja l'interrogant següent: quan Ramón de la Cruz introduïa el català en El café... d'una forma tan notable, fins a quin punt servia el seu ideal de versemblança, o fins a quin punt seguia un costum preexistent d'introduir el català en les peces curtes més del gust del poble menut? En quina mesura el català era una pàtina més de costumisme tan habitual en ell, i en quin grau pretenia assegurar-se l'èxit servint un públic i un costum preexistent? Tots aquests interrogants ens porten a pensar que sembla evident que algun hàbit de posar sobre les taules peces curtes bilingües o en català deuria d'existir en el Teatre de Barcelona abans de l'arribada dels dramaturgs del tombant del segle com Manuel Andreu Igual, Ignasi Plana, Robrenyo, etc.

Creiem que si continuem garbellant els centenars de sainets que es van estampar en el tombant de segle, és molt possible que hi trobàrem altres exemples bilingües que podrien arrodonir la mostra i, potser, ens permeteren aproximar-nos al punt en què aquesta tendència s'hi va fer ben visible. Fins a quin punt aquesta pràctica podria ser poc o molt anterior al darrer terç del segle? És una qüestió difícil de resoldre, i més en el 
context concret del teatre comercial o oficial, en què no era habitual que les peces breus quedaren reflectides, amb detall, en la cartellera.

\section{De Ramón de la Cruz a Josep Robrenyo ${ }^{8}$}

Potser és el moment de reprendre les paraules de Curet, i també les de Fàbregas, i de parlar d'algunes de les obres del saineter madrileny. Cal dir que, tal com havia reportat el testimoni de Curet, De la Cruz és autor d'El café de màscaras (177?) ${ }^{9}$-a més d'El café de Barcelona-, però també d'El sarao (1764), d'El reverso del sarao (1766), El baile de máscaras (1768) o El sarao de Chinita (1777). Tots aquests (més el de Los saraos de compañeros que se hacen en Barcelona), són títols que ens interessen perquè es poden relacionar temàticament amb l'obra de Robrenyo, Juan y Eulalia o El sarau de la Patacada (1805/1825).

Pel que fa a la popularitat dels balls de màscares, des de la noblesa fins al poble menut, és un tema fora de tot dubte i no és aquest el moment, ni disposem de l'espai necessari, per a parlar-ne amb cert detall. El que sí que ens sembla és que uns títols i altres palesen la popularitat dels balls de màscares, del sarao, com a "tema" recurrent en les peces breus que pujaven a l'escena durant tota la segona meitat del segle XVIII. Ramón de la Cruz -entre alguns altres que el seguien- insistia una i altra vegada, en general, per denunciar els excessos que s'hi produïen (en organitzar una festa per tal d'aparentar el que no s'és, en la despesa efectuada per assistir-hi, en el pelatge social, famolenc o moral dels que hi assistien, en les conseqüències, etc.); i una i altra vegada les obres eren un èxit de públic.

El teatre del madrileny arribava a Catalunya per diverses vies que confluïen a difondre els seus títols: les valoracions positives o negatives que mereixien les seues obres en el curs del debat de la introducció de l'estètica (i de l'escena) neoclàssica; el ressò dels seus èxits de públic a Madrid o de la mateixa polèmica generada pels seus detractors (i animada pel mateix dramaturg) a través de les gacetes i altres fulls eixits

\footnotetext{
${ }^{8}$ L'espai d'aquest treball no em permet d'entretenir-me a contextualitzar la vida i l'obra de Josep Robrenyo, de sobra conegudes pels especialistes del teatre català d'aquesta època, o a situar l'estrena de la peça que ens ocupa. Remet el lector interessat a la bibliografia final.

${ }^{9}$ Es tracta d'una de tantes obres populars i, alhora, mal conegudes del prolífic saineter. El seu biògraf, Emilio Cotarelo (1899), que féu una primera catalogació de tota l'obra, gairebé no en diu res d'aquest títol. Això no obstant, vegeu també les reserves quant a l'atribució d'aquesta peça a Ramón de la Cruz manifestades per Mireille Coulon (1996: 280), segurament la més qualificada dels estudiosos de l'obra del dramaturg madrileny.
} 
d'impremta; a través de les companyies que posaven en escena les seues obres a tot arreu (les cartelleres ens ho demostren a bastament: Par 1929, Sala Valldaura 1999, Suero Roca 1987-1997, etc.) i, molt particularment, la impremta. No disposem de catàlegs dels centenars de sainets que es van estampar en plecs solts en les impremtes catalanes $\mathrm{i}$ valencianes, però amb una simple consulta als catàlegs sobre els fons conservats en algunes biblioteques, de seguida ens adonem de la importància d'establiments tipogràfics com el de Joan Francesc Piferrer, Pau Nadal o Carles Gisbert i Tutó, a Barcelona, o els d'Orga o Estevan, a València, entre altres. El fet de la condemna de l'entremés per part dels neoclàssics i la seua retirada gradual d'escena després de 1780, no va fer més que entronitzar els sainets de Ramón de la Cruz i companyia, per a la desesperació dels dramaturgs seguidors de Luzán, com el mateix Moratín.

Per la seua banda, el que fa l'apuntador Martínez és molt simple: traslladar el tema madrileny del sarao a Barcelona i atorgar-li color i sabor locals. Si tenim en compte que l'autor molt possiblement féu d'apuntador del Teatre de Barcelona en aquests anys i que, a més, alguns dels actors que van posar en escena Los saraos de compañeros (Ildefonso Coque, Manuel Florentín i José Morales), apareixen com a empresaris del mateix teatre des del 24 de març de 1785 fins al 26 d'octubre de 1787; que altres actors que van participar en la mateixa funció figuren durant el mateix període com a membres de la companyia del teatre (Dama $1^{\mathrm{a}}$, Manuela Martínez, $2^{\mathrm{a}}$ Francisca Morales, Galan $1^{\circ}$, Manuel Florentín), o s'hi van incorporar en la temporada de l'any 1788, com Victoria Ibáñez, José Galán, Justo Germán, Ángel Blasón, etc. (Par 1929: 494-512), no és d'estranyar, doncs, que l'obra quedara en el repertori del teatre. El mateix teatre de Barcelona on va arribar, uns anys després, Robrenyo per fer-hi de meritori i espai en el qual es va representar Juan y Eulàlia l'any 1805 (Suero Roca 1987: II, 182). Si més no, unes circumstàncies i altres reforçarien l'autoria de Robrenyo en relació a aquest títol (Vegeu Mas i Vives 1996: 108).

\subsection{El café de máscaras vs Juan y Eulalia o El sarau de la Patacada}

Els punts de contacte entre les dues obres són molt evidents. En la primera, dos vells amics, de condició i d'edat, Mauro i Quiroteca, es junten per anar a veure un ball de màscares i comprovar com s'hi diverteix la gent del dia. A la porta del ball (primera part de l'acció) observen l'arribada de Manuel, que fa de cortejo d'una dona casada, que no 
té diners per a regalar-la, però que és capaç de grans sacrificis propis per tal d'obsequiar-la; i de Julia, la dona, i Niso, el marit, amb poques ganes d'aquella d'anarhi acompanyada pel propi, etc. Al costat mateix del ball, hi ha el café (on transcorre la segona part de l'obra). El dos personatges inicials, Mauro i Quiroteca, asseguts al café observen la torbació de Niso, en haver perdut la dona al mig del ball (la qual se n'ha anat a buscar a Manuel, el seu cortejo), i només la pot identificar per la disfressa de gitana que du posada; aquesta disfressa genera una confusió amb una altra dona que du un vestit semblant, i amb l'acompanyant d'aquesta, amb el qual arriben a les mans. Com a resultat de l'accident patit per Niso, el duen al café, on arribaran Manuel, Julia, i altres personatges que, per a raonar entre ells es lleven les màscares, i s'hi produeix la moralina. Niso troba la dona acompanyada de Manuel, però també una cosina (i les seues filles), que fa uns dies que ha quedat vídua i ja és al ball; però Don Mauro, que critica aquesta degeneració de la moral en relació als seus temps, també trobarà la seua filla al café, que ell creia dormint a casa i tancada amb pany i clau.

El sarau de la patacada, parteix del matrimoni Juan i Eulàlia, ell barber, foraster de Madrid, de caràcter greu i poc amant dels balls, i ella barcelonina, mestressa de casa i amant de la festa. En la primera part de l'obra, a casa d'Eulàlia compareix, primer, una antiga senyora a la qual ella havia servit, per demanar-li una vestimenta de menestrala per anar al sarau, on va el seu marit, d'amagat, al qual vol sorprendre. Acte seguit, una veïna, i Eulàlia, animada per aquesta, crea un ardit per enviar Juan a dormir i així, mentre aquest dorm, poder anar honestament al ball una estona i veure'n l'ambient. Però Juan es desperta, troba que la dona no hi és i de seguida pensa que se n'haurà anat a la Patacada. Se n'hi va desesperat, i s'hi produeix l'escena de la confusió dels vestits, amb l'antiga mestressa d'Eulàlia, i el marit d'aquesta i un amic, que es riuen de Juan. Eulàlia, que ha vist el seu marit entre la gentada, se'n torna a casa per no ser descoberta. Juan, en arribar-hi, es penedeix de la seua desconfiança fins que, al final, el fill de la veïna descobreix involuntàriament l'engany d'Eulàlia. És en aquest moment quan es produirà el parlament del marit amb la moraleta final, molt en la línia del que podem trobar en l'obra (i obres) de Ramón de la Cruz.

Com podem comprovar, la intriga, el conflicte, la dona que per unes raons o altres va al ball sola, el marit desesperat que busca la dona, la confusió de les disfresses, les referències al café, o la mateixa divisió en dos espais, etc. palesen el deute de l'autor 
català respecte del castellà. Si de cas, cal notar que l'obra de Robrenyo, a més de ser bilingüe, és uns 130 versos més llarga que la del madrileny.

És més, algunes referències urbanes, d'oficis o de condició social del text de Robrenyo (carrer de 1'Hospital, Voltes dels Encants, davant de Santa Maria, Boqueria, mestre de cases, venedora, pubilla, o els antropònims catalans que s'hi fan servir), ens fan pensar en l'obra de Los saraos de compañeros. El procediment de projectar l'acció sobre el marc urbà de la ciutat de Barcelona per guanyar en versemblança és el mateix.

\subsection{La novetat de Juan y Eulalia o El sarau de la Patacada}

Prescindint ara de la qüestió de si el text que ha arribar fins a nosaltres és el mateix que es va estrenar l'any 1805 o si és la versió posada en escena vint anys després (Sala Valldaura 2006: 149-150; Anguera 2004: 15), el fet cert és que si, com acabem de veure, el tema dels balls de màscares era força conegut, era habitual en el repertori del teatre breu, si els títols esmentats de Ramón de la Cruz eren tan populars, i si el conflicte que planteja Robrenyo no era gens nou, on rau la clau de l'èxit de la peça?

En part, ja ens ho havia apuntat Curet (1917: 84-85):

Los personajes catalanes que intervienen en el Sarau de la Patacada, conservan la peculiar fisonomía de los ciudadanos barceloneses y los forasteros no se presentan como altaneros y despreciativos para con las costumbres de la ciudad, sino casi identificados con ellas, siguiendo la ley constante de que todas las corrientes emigratorias que vienen a parar a Barcelona, asimílanse en definitiva a la naturaleza catalana. Aparece en el Sarau el "lechuguino", variedad barcelonesa del "sietemesino", y muchas de las frases y donaires que figuran en la obra, son de repertorio todavía en el vocabulario de nuestras clases populares.

I això Robrenyo ho aconsegueix allargant la part catalana, passant dels 70 versos que tenia Los saraos..., als 343 que té El sarau..., i arribant gairebé al 45\% del text de l'obra (la resta són versos castellans). Això li permet aprofundir en el camí que havia desbrossat Juan Manuel Martínez: agafar un tema o un argument d'èxit de Ramón de la Cruz i afaiçonar-lo en l'entorn urbà de Barcelona, per fer-hi parlar amb fluïdesa uns personatges versemblants i representatius de la menestralia de la ciutat. Si en l'original el marc és Madrid, ara serà Barcelona, si allà els tipus humans són la maja, el 
currutaco, el cortejo, etc. aquí seran els menestrals (Eulàlia, la veïna Gràcia, Batalla o Brinça), i, en part, senyorets Don Carlos, Don Luis i Donya Matilde, que són tipus que en cap cas poden ser considerats com a petimetres o currutacos. És en aquest procés que Robrenyo crea, potser, el primer, o un dels primers, tipus dramàtics del que serà el nou teatre dramàtic vuitcentista català. I ho fa dotant-lo d'una llengua viva, urbana, molt pròxima a l'espectador popular i allunyada de l'encarcarament dels precedents que hem vist $i$, fins a cert punt, del llenguatge del vell entremés.

Per cloure, direm que sembla clar que el tema triat per l'autor no era "estrany" per al públic al qual anava adreçada l'obra. Ans al contrari, es tractava d'una temàtica, que tot i ser una mica vella, era coneguda i popular i que, a més, en el Teatre de Barcelona ja comptava amb un precedents molt clars. I ara el poble menut s'hi veia reflectit i s’identificava en els personatges creats per Robrenyo. El camí del nou teatre català quedava delimitat clarament.

\section{A tall de conclusió}

Sembla clar que, com insinuava Fàbregas, "per comprendre l'ascendent dels saineters catalans de finals del XVIII i començament del XIX", cal mirar amb detall els dramaturgs populars de la segona meitat del Set-cents, i particularment els textos en un acte que van eixir dels establiments tipogràfics catalans o valencians. Perquè des del nostre punt de vista, és gairebé sempre a partir d'aquests plecs que alguns autors catalans del tombant del segle o primera meitat del XIX, apedaçaran temes i textos, per fer-ne versions diferents en l'idioma del país. És el cas de Vicent Albertí, el més conegut i més internacional, perquè estrafà o adapta textos de Goldoni, Molière o Metastasio, a més de Ramón de la Cruz (Pons i Pons 1994; Salord 1997; Paredes 1999 o Miralles 2007), però també de Josep Bernat i Baldoví (Sansano 2002), d'Eduard Escalante, o del mateix Josep Robrenyo, com acabem de veure. També el cas de Francesc Renart, que tractarem en un estudi pròxim.

L'impacte del sainete castellà de la segona meitat del segle XVIII, sobretot a través de la impremta, és molt més pregon del que ens havíem pensat fins ara. Gairebé tots els primers sainets costumistes en català del XIX tenen com a model les peces d'ambients costumistes posades de moda per Ramón de la Cruz i els seus coetanis. En aquest context, cal pensar que De la Cruz és el model dramàtic que permet superar el vell entremés (simple recialla en el tombant del segle) i projectar un nou teatre 
costumista des d'una òptica autòctona i, gairebé, urbana. En contra del que han manifestat alguns historiadors i crítics del teatre, creiem que cal relativitzar la importància i l'interès del vell entremés català en l'aparició d'aquest nou teatre.

\section{REFERÈNCIES BIBLIOGRÀFIQUES}

AmAdeS, Joan. 1937. Auca dels costums de Barcelona, Barcelona, [s.n.].

AnguerA, Pere. 2004. "Estudi introductori” dins Josep Robrenyo, Teatre català, a cura d'Albert Mestres, Tarragona, Arola Editors, I, 9-36.

ARTís, Josep. 1933. "Josep Robrenyo, autor i comediant" dins Josep Artís, Tres conferències sobre teatre retrospectiu, Barcelona, Institució del Teatre, 171-245.

CASTELls I AltiRriBA, Joan. 1975. "Materials relatius al teatre català profà dels segles XVIII i XIX», Estudios escénicos 19, 13-46.

Cotarelo y Mori, Emilio. 1899. Don Ramón de la Cruz y sus obras. Ensayo biográfico y bibliográfico, Madrid, Perales y Martínez.

Coulon, Mireille. 1996. "De lo difícil que es devolverle al césar de los saineteros lo que le pertenece" dins Josep Maria Sala Valldaura (ed.), Teatro español del siglo XVIII, Lleida, Universitat de Lleida, 265-287.

CRUZ, Ramón de la. 1788. El café de Barcelona, Barcelona, Francisco Generas.

CRUZ, Ramón de la. 1915-1928. Sainetes, en su mayoría inéditos, a cura d'E. Cotarelo y Mori, Madrid, Bailly-Bailliere, 2 vols.

CRuZ, Ramón de la. 1944. El café de máscaras, El sarao i El reverso del Sarao, dins Sainetes, Madrid, Aguilar, 213-250, 539-574 i 575-626.

CRUZ, Ramón de la. 1988. La mahonesas, Ciutadella, Ediciones Nura [reproducció facsímil de l'edició de 1900].

CURET, Francisco. 1917. El arte dramático en el resurgir de Cataluña, Barcelona, Minerva.

FÀBREgAS, Xavier (ed.). 1967. Sainets de la vida picaresca, 1800-1868, Barcelona, Edicions 62.

FÀBREGAS, Xavier. 1975. Les formes de diversió en la societat catalana romàntica, Barcelona, Curial.

FERnÁNDEZ Gómez, Juan F. 1993. Catálogo de sainetes y entremeses del siglo XVIII, Oviedo, Instituto Feijoo de Estudios del siglo XVIII. 
IZQUIERDO IZQUIERDO, Lucio. 1990. "El teatro menor en Valencia (1800-1850)", Revista de Literatura LII, 101-127.

Llates, Rossend. 1944. Las fiestas populares barcelonesas, Barcelona, Llibreria Dalmau; reed. Barcelona, Alba, 1983.

MARTíneZ, Juan Manuel. 1788. Los saraos de compañeros que se hacen en Barcelona, Barcelona, Viuda de Piferrer.

MAS I VIVES, Joan. 1996. "Esquema per a una revisió del teatre català del segle XIX" dins Miscel·lània Germà Colón, Barcelona, 1996, 107-123 (Estudis de Llengua i Literatura Catalanes, XXXIII).

MASSIP, Francesc. 2007. Història del teatre català, Tarragona, Arola, I.

MCKNight, William A.-Mabel BARRET Jones. 1965. A Catalogue of Comedias Sueltas in the Library of the University of North Carolina, University of North Carolina Library.

MirALLES, Eulàlia. 2007. "Vicenç Albertí, traductor de Metastasio" dins Jordi Malé \& Eulàlia Miralles (eds.), Mites clàssics en la literatura catalana moderna $i$ contemporània, Barcelona, Universitat de Barcelona, 39-58.

MoLL, Jaime. 1964-1966. "Catálogo de comedias sueltas conservadas en la Biblioteca de la Real Academia Española”, Boletín de la Real Academia Española XLIV (1964), 113-168, 309-360 i 541-556; XLV (1965), 203-235; XLVI (1966), 125158 .

Moll, Jaime. 1968-1972. "La serie numerada de comedias de la imprenta de los Orga", Revista de Archivos, Bibliotecas y Museos LXXV, 1-2, 365-456.

PAR, Alfonso. 1929. "Representaciones teatrales en Barcelona durante el siglo XVIII, Boletín de la Real Academia Española XVI, 326-346, 492-513 i 594-614

PARedes BAUlidA, Maria. 1999. "Traductors i traduccions a la Menorca il-lustrada" dins Francisco Lafarga (ed.), La traducción en España (1750-1830). Lengua, literatura, cultura, Lleida, Universitat de Lleida, 79-89.

Pessarrodona, Aurèlia. 2006. "Catálogo descriptivo de libretos de tonadillas impresos en Barcelona en el siglo XVIII”, Recerca musicologica XVI, 17-63.

Pessarrodona, Aurèlia. 2008. “Aportaciones al estudio del uso del catalán en el teatro barcelonés del siglo XVIII a partir de la tonadilla escénica", dins Joaquín Álvarez Barrientos \& Begoña Lolo (eds.), Teatro y música en España. Los 
géneros breves en la segunda mitad del siglo XVIII, Madrid, CSIC-UAM, 117131.

PoBlet, Josep Maria. 1980. Josep Robrenyo. Comediant, escriptor i revolucionari, Barcelona, Millà.

PONS I PONS, Joan-Antoni. 1984. "Vicenç Albertí i Vidal, traductor menorquí del segle XIX”, Els Marges 31, 107-114.

ROBERT, Robert. 1935. Estampes del segle XIX, Barcelona, Lliberia Catalònia.

Robrenyo, Josep. 1914. El sarau de la Patacada, Barcelona, Artís \& Co.

RoBrenyo, Josep. 2004. Teatre català, a cura d'Albert Mestres, Tarragona, Arola Editors, 2 vols.

Sala Valldaura, Josep Maria. 1999. La cartellera del Teatre de Barcelona (17901799), Barcelona, Curial-Publicacions de l'Abadia de Montserrat.

Sala Valldaura, Josep Maria. 2000. El teatro en Barcelona, entre la Ilustración y el Romanticismo, Lleida, Milenio.

Sala Valldaura, Josep Maria. 2005. "El fet teatral a la ratlla de 1800”, Anuari Verdaguer, 13 (2005), 327-353

Sala Valldaura, Josep Maria. 2006. Història del teatre a Catalunya, Vic, Eumo

Sala Valldaura, Josep Maria. 2007. "Introducció", dins Teatre burlesc català del segle XVIII, Barcelona, Barcino, 5-118.

SALORD RIPOLL, Maite. 1997. "Vicenç Albertí i Vidal: la traducció com a exercici de (re)creació literària”, dins V. Albertí i Vidal, Entremesos, Maó, IME, I, 7-31.

SANSANO, Gabriel. 2002. "Sobre els antecedents dramàtics de Josep Bernat i Baldoví" dins M. Nicolás (ed.), Bernat i Baldoví i el seu temps, València, Universitat de València, 429-448.

SANSANO, Gabriel. (en premsa). "De l'herència barroca al quadre de costum: les primeres passes del teatre vuitcentista" in La construcció contemporània del sistema lingüisticoliterari català. VII col·loqui Verdaguer, Anuari Verdaguer 17.

SuERo RocA, Maria Teresa. 1987-1997. El teatre representat a Barcelona de 1800 a 1830, Barcelona, Institut del Teatre.

Sullivan, Howard A. \& Henry N. Bershas. 1984. The Wayne State University Collection of Comedias Sueltas. A Descriptive Bibliographie, Detroit, Wayne State University Press. 
VillalongA, Anna-Maria. 2008. "El "serial" d'en Saldoni i la Margarida: una mostra de la casuística del sainet català". Estudis de Llengua i Literatura Catalanes/ LVI. Miscel·lània Joaquim Molas, 1, Barcelona, PAM, 2008, 61-88. 